Original Research

\title{
Indicators and Index of Elderly Well-Being to Support an Age-Friendly City
}

\section{Pipit Festi Wiliyanarti' ${ }^{1}$, Hari Basuki Notobroto ${ }^{2}$, Hamidah Hamidah ${ }^{3}$, and Erfan Rofiqi $^{4}$}

${ }^{1}$ Faculty of Health Science, Universitas Muhammadiyah Surabaya, Surabaya, Indonesia

${ }^{2}$ Faculty of Public Health, Universitas Airlangga, Surabaya, Indonesia

${ }^{3}$ Faculty of Psychology, Universitas Airlangga, Surabaya, Indonesia

${ }^{4}$ Student, Master in Nursing Programme, Faculty of Nursing, Universitas Airlangga, Surabaya, Indonesia

\begin{abstract}
Introduction: Increasing the life expectancy of the elderly raises complex problems concerning the life aspects of the elderly, family, community, and government. A well-being indicator for the elderly is needed as a measurement tool to facilitate Indonesian elderly individuals to becoming more prosperous. The purpose of this study was to develop well-being indicators and to formulate the elderly well-being Index.
\end{abstract}

Methods: This study used an explanatory research design with a quantitative approach. In total, 400 respondents were collected using multistage random sampling. The physical well-being variable used the Mini-Mental State Examination (MMSE) instrument, Barthel's index, and the Disease Complaint questionnaire. In addition, a psychology and social well-being instrument, social well-being instrument, and spiritual instrument were employed. Confirmatory Factor Analysis was used to verify the factor structure of all of the observed variables.

Results: The results showed that the indicators for elderly well-being are demographic with the following factor loading: $(\lambda) 0.32$, social environment $(\lambda)=0.51$, health services $(\lambda)=0.55$, physical well-being $(\lambda=0.36$ psychological wellbeing $(\lambda)=0.46$, social well-being $(\lambda)=0.45$ and spiritual well-being $(\lambda)=0.50$. The indicators and index can be used as an effort to drive the program, so then the elderly can become productive, prosperous, and meaningful.

Conclusion: The elderly well-being index is expected to be a programmatic instrument that can measure and evaluate the welfare of the elderly. This will increase the elderly health program that is available to achieve more holistic wellbeing and an age-friendly city.

\section{ARTICLE HISTORY}

Received: Dec 12, 2019

Accepted: March 09, 2020

\section{KEYWORDS}

age-friendly city; elderly; indicators; index; well-being

\section{CONTACT}

Pipit Festi Wiliyanarti $\triangle$ pipitfesti@fik.umsurabaya.ac.id

$\doteq$ Faculty of Health Science, Universitas Muhammadiyah Surabaya, Surabaya, Indonesia

Cite this as: Wiliyanarti, P. F., Notoboroto, H. B., Hamidah, H., \& Rofiqi, E. (2020). Indicators and Index of Elderly WellBeing to Support an Age-Friendly City. Jurnal Ners, 15(1), 19-25. doi:http://dx.doi.org/10.20473/jn.v15i1.16683

\section{INTRODUCTION}

A growing elderly population has an impact when trying to improve the quality of life. Human wellbeing is one of the most popular fields of modern multidisciplinary research. The issue is topical due to the conclusions that it is on economic and social change. More than $25 \%$ of the world population will fall into the category of being elderly by 2050 (Global Age Watch Index, 2014). This also has an impact on the increasing growth of Indonesia's elderly population. The increase in aging is estimated to reach 63.31 million in 2045, which is around $20 \%$ of the population (Bps, 2018). Elderly needs are not only related to meeting their physical and financial needs that are currently the focus, but it also refers to their overall needs in life. At present, the increase in the number of elderly residents is not accompanied by an increase in the well-being of the elderly (Lifshitz, Nimrod and Bachner, 2019).

The view of well-being lies in the approach used in interpreting well-being. Well-being starts from the study of social and economic perspective approaches, where social well-being is a state of human life that is 
created when facing various social problems that can be managed properly (Fave et al., 2018). The wellbeing study in this research uses being 60 years of age and over to refer to the elderly, which includes their physical, psychological, social, and spiritual wellbeing. The elderly group that is the target of this development is also the concern of the Surabaya city government (Bps, 2018) of East Java. At present, the problem of the elderly is the focus of a study conducted by the province of East Java, especially the city of Surabaya. One of the development goals in East Java is to improve the well-being and quality of life of the people, including the elderly in East Java. In line with that, the formulation and direction of development policies are aimed at empowering and improving well-being. However, the program's achievements are not yet clear. The concern for older individuals about their well-being is closely related to their health condition. As an individual get older, their health declines and may worsen due to the constraints faced when maintaining their health (Ivankina and Ivanova, 2016). At present, the Indonesian government has launched an elderlyfriendly city program (Hermawati, 2015). The acceleration program for achieving an elderlyfriendly city is one of the efforts undertaken to anticipate the explosion of the elderly in Indonesia by 2035. The explosion will have an impact on the socioeconomic burden of the state (Global AgeWatch Insight, 2018).

The Indonesian government does not have any indicators, nor an index prepared to measure the well-being of the elderly. Well-being indicators use individual income guidelines, but this was a different concept between welfare and well-being (Wiliyanarti et al., 2017). The availability of appropriate indicators will help the Indonesian government determine the scale of the priorities and targets of well-being development. If there are no indicators or well-being indexes available, the government will experience difficulties when trying to determine the well-being category of the elderly for certain individuals or regions (Wiliyanarti, Asri and Putra, 2018). This will have an impact on the development of the elderly well-being program. It is important to understand that index numbers do not only measure a variable or indicator. They can measure several indicators at the same time. Advances in technology and knowledge require an effective method to be able to find a change in relation to the welfare of the elderly (Wiliyanarti, 2018). An index number is a simple statistical measure that can indicate a difference in the individual (elderly), so then the value and category of the index are known.

Based on the concept of health, according to Fleuret and Atkinson (2007), it conveys that wellbeing is a perfect state that includes physical, mental, social, and spiritual well-being. It does not mean being free from disease only. This indicator does not mention in detail the symbols used for each component, making it difficult to measure the achievement of well-being because it is still too general. The well-being of the elderly in various regions has not been measured using the same indicators.

Therefore, in order to be able to assess the level of well-being of the elderly, it is recommended to use the elderly well-being index as an additional method paired with the use of the existing indicators. The availability of appropriate indicators will assist the government in determining the scale of the priorities and targets of well-being development. If there are no indicators or well-being indexes, the government will have difficulty identifying the well-being categories of the elderly for certain individuals or regions. This will have an impact on the development of the elderly well-being program. The study aimed to develop the elderly well-being indicators and subsequently to formulate the Elderly Well-being Index in Surabaya.

\section{MATERIALS AND METHODS}

This study aimed to develop indicators for the wellbeing of the elderly. The research was conducted in two stages. The first stage used a qualitative approach presented in the form of a descriptive exploration (Burhan Bungin, 2005).

The study design used was an explanatory research study with a cross-sectional approach. The population was all of the elderly living with familiesthe study conducted in a selected village in the city of Surabaya. The sample was in the working area of the primary health care services of Surabaya (East, West, Central, North, South), totaling as many as 400 respondents. The sampling method used in this study was Multistage Random Sampling. The research variables were physical, psychological, social, and spiritual well-being. At the quantitative research stage, the research instruments were in the form of structured questionnaires. The instrument was created after the first research phase was completed when the indicators had been collected qualitatively. The indicators that were collected were used as material for instrument development. The instruments used were for physiological well-being (Ryff, 2014), social well-being (Ryff, 2014), and spiritual well-being (Gomez and Fisher, 2016). Modifications in terms of the instrument theme studies are associated with elderly well-being. The indicators tested for validity and reliability were psychological well-being with a value of 0,691 , social well-being with a value of 0.7 , spiritual well-being with a value of 0.971 , social environment with a value of 0.7 and the health service factor with a value of 0.8 . The instruments that were not tested for validity and reliability were the indicators for the demographic factors and physical well-being. This study was approved by the Ethics Committee number 37-KEPK in 2016.

\section{RESULTS}

Based on Table 1 above, it is known that the majority of the elderly were aged $60-69$ at $68.3 \%$, that women made up $80.8 \%$, and that the percentage for those not 
Table 1. Characteristic of Respondents $(n=400)$

\begin{tabular}{lcc}
\hline Characteristics & n & \% \\
\hline Age & & \\
60 - 69 years old & 273 & 68.3 \\
70 - 79 years old & 113 & 28.3 \\
> 80 years old & 14 & 3.5 \\
Gender & & \\
Man & 77 & 19.3 \\
Woman & 323 & 80.8 \\
Income status & & \\
Have an income & 133 & 33.3 \\
Don't have an income & 267 & 66.8 \\
Expenditure & & \\
Expenditure 40\% of income & 135 & 33.8 \\
Expenditure 41\% - 60\% of income & 143 & 35.8 \\
Expenditure >60\% of income & 122 & 30.5 \\
Occupation & & \\
Working & 87 & 21.8 \\
$\quad$ Un-employed & 313 & 78.3 \\
Marital status & & \\
Married & 254 & 63.5 \\
Divorced & 14 & 3.5 \\
Widow/widower & 128 & 32.0 \\
Un-married & 4 & 1.0 \\
Education & & \\
No education & 27 & 6.8 \\
Elementary school & 107 & 26.8 \\
Junior High School & 96 & 24.0 \\
Senior High School & 95 & 23.8 \\
Diploma & 23 & 5.8 \\
Bachelor's & 51 & 12.8 \\
\hline & & \\
& &
\end{tabular}

working was $78.3 \%$. The percentage of those who had no income was $66.9 \%$, and $63.5 \%$ were married. Expenditures most commonly made up $41 \%-60 \%$ of any income, and the most common level of education was $26.8 \%$ for elementary school.

Based on table 2, the factor loading value of the 27 valid indicators, the factor score was calculated (Table 2). Based on the data above, it can be seen that out of the seven indicators. All indicators have a factor loading value above 0.3. The Confirmatory Factor Analysis (CFA) model for elderly well-being showed that the indicators that have the highest factor loading value were health services $(\mathrm{X} 3=0.55)$ spiritual $(\mathrm{Y} 4=0.50)$, social services $(\mathrm{X} 2=0.51)$, psychological $(\mathrm{Y} 2=0.46)$, social $(\mathrm{Y} 3=0.45)$, physical $(\mathrm{Y} 1=0.36)$, and demographics (X1=0.32).

The results are known to all of the indicators with a factor loading value $>0.4$ or value of $t \lambda>1.96(\alpha=$ $5 \%$ ). Thus, be concluded that the seven indicators above are valid to use to measure the well-being of the elderly. Based on the results of Table 3 , the Elderly Well-being Index Formulation can include the addition of $0,3(\mathrm{X} 1)+0,51(\mathrm{X} 2)+0,55(\mathrm{X} 3)+0,36(\mathrm{Y} 1)$ $+0,46(Y 2)+0,45(Y 3)+0,50(Y 4)$, after which the index value is categorized. The categorization of prosperity is $15.50-19.35$, while well-being is sufficient $19.36-23.20$, and prosperity is 23.21-27.05 (Table 3).

\section{DISCUSSION}

The indicator of demographics can be explained by education and income. The education achieved by the elderly contributes to the perception of the elderly regarding well-being. The income of the elderly made it known that most of the elderly do not have an income. Meeting their needs in everyday life is a cost borne by the family (Bps, 2018). For the elderly individuals that do have an income, this shows that there are still elderly who are actively working to fulfill their daily needs, or just to fill their spare time. They may also have a pension fund (Hyde, Maher and Elavsky, 2013). The ability of the elderly to meet their daily needs and to be able to help other families is an old formula for financial happiness (Kirkwood and Cooper, 2014). The elderly in the community have different well-being levels depending on if the elderly can adapt and go through the aging process.

The health service indicators explained that health services had become one of the components in the well-being of the elderly. The factor loading meets the standard criteria. It can be stated that the social environment and service guarantees are the indicators of the well-being of the elderly. According to the research, the social environment being optimal is a condition that is needed by the elderly (Burton, Mitchell and Stride, 2011). The environment determines the achievement of well-being for the elderly. Health insurance is one of the health efforts that the elderly need. When the elderly individual becomes sick, fulfilling health insurance is needed. The elderly health services in Indonesia are facilitated by the existence of the Elderly Health Services Post. The benefits of the Health Services Post for the elderly that it was a community-based service effort, among others. It seeks to improve the health status of the elderly, increasing their independence, slowing the aging process, and allowing for the early detection of health problems and increasing their life expectancy (Erpandi, 2015). The elderly way of life in the environment is very influential in the development of the elderly. The environmental conditions can provide support to increase the interest of the elderly to achieve a better sense of overall well-being (Wiliyanarti, Notobroto and Asri, 2017). A thriving environment is an environment that can improve the physical health, psychological well-being and social needs of those within it (Othman and Fadzil, 2020)

Successful or optimal old age emphasizes that the elderly have three relevant components: avoiding disease, the ability to work, and the ability to interact socially. The existence of disease is an indicator of the physical well-being of the elderly. This was stated by several elderly (Hyde, Maher and Elavsky, 2013). The physical condition is affected by the disease, which can reduce the life satisfaction of the elderly. Physical functioning and elderly cognition are also indicators of physical well-being. Changes in the organic and systemic systems vary greatly, both between individuals and within individuals as well (Kirkwood and Cooper, 2014). Aging with chronic stress can 


\section{P. F. WILIYANARTI ET AL.}

Table 2. Well-being Indicators based on Loading Factor

\begin{tabular}{|c|c|c|}
\hline Factors & Indicators & Factor Loading $(\lambda)$ \\
\hline \multirow[t]{4}{*}{ Demography } & 1. Level of expenditure & 0.41 \\
\hline & 2. Occupation & 0.71 \\
\hline & 3. Marital status & 0.30 \\
\hline & 4. Education & 0.49 \\
\hline \multirow[t]{3}{*}{ Social environment } & 1. Social network & 0.78 \\
\hline & 2. Family and community environment & 0.68 \\
\hline & 3. Problems & 0.59 \\
\hline \multirow[t]{3}{*}{ Health services } & 1. Elderly services & 0.80 \\
\hline & 2. Access information & 0.69 \\
\hline & 3. Health insurance & 0.73 \\
\hline \multirow[t]{4}{*}{ Physical well-being } & 1. Independence & 0.71 \\
\hline & 2. Complaints of physical health & 0.54 \\
\hline & 3. Cognitive function & 0.64 \\
\hline & 4. Disease suffered & 0.58 \\
\hline \multirow[t]{6}{*}{ Psychological well-being } & 1. Self-acceptance & 0.76 \\
\hline & 2. Purpose of life & 0.49 \\
\hline & 3. Control of the environment & 0.68 \\
\hline & 4. Personal development & 0.59 \\
\hline & 5. Positive relationship & 0.60 \\
\hline & 6. Autonomy & 0.59 \\
\hline \multirow[t]{3}{*}{ Social well-being } & 1. Social acceptance & 0.88 \\
\hline & 2. Social actualization & 0.71 \\
\hline & 3. Social contributions & 0.94 \\
\hline \multirow[t]{4}{*}{ Spiritual well-being } & 1. God & 0.92 \\
\hline & 2. Personal & 0.87 \\
\hline & 3. The environment & 0.88 \\
\hline & 4. Communal & 0.91 \\
\hline
\end{tabular}

reduce immune function, making the elderly more vulnerable to getting an infection. The digestive system can still be quite efficient even though the elderly are more at risk of malnutrition. The elderly have a heart functioning level that is slower and irregular, often due to the occurrence of obesity in the elderly. This also increases blood pressure (Kirkwood and Cooper, 2014).

Nevertheless, there are still many elderly individuals who do not pay attention to the changes in their systemic functions. The elderly abilities related to cognitive function also experience changes, but not all changes in the brain are destructive. Changes in cognitive function are not fundamental, and they do not significantly affect cognition, although there are increased brain changes. Cognitive decline tends to increase (Papalia, Olds and Feldman, 2009). The physical activity carried out by the elderly is closely related to the level of well-being, normally referring to the activities carried out by individuals without assistance. However, this was different for each age group where the elderly experience physical decline (Hyde, Maher and Elavsky, 2013). This was also stated by (Roberts et al., 2017), who stated that the ability to carry out basic activities could be used to refer to the continuation of old age and the desire to remain independent and to have a good quality of life. The ability to work independently contributes significantly to the quality of life of the elderly, and it is associated with psychological well-being (Fave et al., 2018).

Psychological well-being, in general, can be interpreted as a form of satisfaction with aspects of life to bring in or cause feelings of happiness and a feeling of peace in one's life. The standard of satisfaction in each person is different, so this is subjective. Based on the results of the study, all of the indicators for psychological well-being can be used to measure psychological well-being, proving that the loading factor's statistical value is above the standard value. (Ryff, 2014) states that a positive attitude, which is a component of psychological well-being, is needed to recognize and accept the various aspects of the self, both positive and negative. They should have positive feelings about their past life. Self-acceptance means that the elderly are able to reflect on the shortcomings that exist in their elderly self. It was included the weakness of the physical condition when aging. This should not be a thing that reduces happiness, but instead, it should result in the sense of acceptance in the form of gratitude. The purpose of life that is possessed by the elderly is also an indicator and component of psychological well-being. Ryff formulates psychological well-being into a multidimensional model (Ryff, 2014). Each dimension describes the efforts made by someone to face different challenges, then the individual functions positively. Individuals who are autonomous means that the individuals have a sense of selfdetermination and that they are free and able to overcome social problems by thinking and acting according to their beliefs. They regulate their behavior from within and evaluate themselves based on their standards. Psychological well-being must be supported by mental health, which is not only about being without a mental illness. Positive mental health involves psychological feelings of well-being that coexist with self-health (Ryff, 2014). Suggested health 
Table 3. Significance of the CFA model on Elderly Well-being

\begin{tabular}{lcccc}
\hline Symbol \& Variables & Factor Loading $(\boldsymbol{\lambda})$ & $\mathbf{t}_{\boldsymbol{\lambda}}$ & $\mathbf{1 - \boldsymbol { \delta }}$ & $\mathbf{t}_{\mathbf{1 - \boldsymbol { \delta }}}$ \\
\hline X1. Demography & 0.32 & 4.49 & 0.90 & 13.47 \\
X2. Social environment & 0.51 & 8.63 & 0.74 & 11.44 \\
X3. Health services & 0.55 & 10.14 & 0.70 & \\
Y1. Physical well-being & 0.36 & 6.20 & 0.87 & \\
Y2 Psychological well-being & 0.46 & 7.63 & 0.79 & 12.15 \\
Y3. Social well-being & 0.45 & 7.50 & 0.80 & 12.23 \\
Y4. Spiritual well-being & 0.50 & 8.36 & 0.75 & 11.65 \\
\hline
\end{tabular}

and social policy approaches include supporting ameliorating an older adults' disability stages which may also contribute to their improved social life and mental health. Preventing functional decline may help to maintain regular social participation and independence in terms of mobility. (Stage 0 ) seems to be crucial to mental well-being. Psychosocial support should be allocated to individuals in higher ADL stages because of their more significant mental health needs. The findings from this study emphasize the salience of the care coordination required to provide complete medical, rehabilitative, psychological, and social care (Na and Streim, 2017).

The social changes that occur in the elderly are related to the physical and cognitive changes experienced by the elderly. Entering a happy old age is the same as being prepared to face changes in all aspects of their life. Social change can be a source of stress if it is not responded to positively (Fave et al., 2018). Many elderly can remain optimal in the social field, and they can achieve conditions that are said to be prosperous (Elo and Isola, 2011). The results of the social well-being Confirmatory Factor Analysis model show that the indicator that has the highest factor loading value was a social contribution. A small loading value was excluded from the model, referring to social relations and social integration. The social well-being indicators are based on the statistical test results for social contribution, social relations, and social inclusion. The results obtained a loading factor result that was more than the standard indicator. Based on these results, it appears that the elderly have both carried out their social roles in the application of daily life, and they have value in the community. The research conducted by Seligman (Diener and Ryan, 2008) shows that the happiest people have good quality social relationships. Relationships that are considered to be useful must include two of the following three social relationships, namely family, friends, and harmonious relationships. Elderly social relations and social integration with the environment are positive behaviors in the environment (Wiliyanarti, Notobroto and Asri, 2017). Most of the elderly can fully interact in society, but the intensity of each individual's interactions shows a difference in the sense that the social relations carried out by the elderly occur only when due to a program or association (Wiliyanarti, Notobroto and Asri, 2017). It also found that the elderly who become cadres and who are active feel happy at being able to socialize. Therefore social relations and social integration cannot yet be a measure to show that these indicators are the components of the social well-being indicators. Elderly well-being is in line with the quality of life, as well as the amount of social relations experienced (Ivankina and Ivanova, 2016).

Spiritual activity is something that can be said to be synonymous with old age activities (Gomez and Fizer, 2016). In societies in various countries, some elderly are made spiritual leaders in various religions, including churches, Muslim communities, and others. Based on the results of research conducted looking into the characteristics of spiritual well-being, the aspect of approaching God and the personal, environmental and communal aspects are in the good category. In this case, it can be interpreted that almost all elderly have fulfilled the criteria for spiritual happiness. The results of the spiritual well-being model show that the well-being components above are declared to be valid. The highest factor loading value is the God indicator. This is in line with spiritual well-being, according to (Gomez and Fisher, 2016). They stated that something is felt about the positive reflections on their behavior and cognition relating to oneself, in addition to society, intuitive feelings and the environment, the ability of individuals to identify themselves alone, commitment, positive attitude, and hormones in life. They also state that the reason for participating in religious activities is related to one's well-being (Diener and Ryan, 2008). A religious belief system helps most people to deal with stress and loss across the life cycle, providing optimism that the later life problems that cannot be overcome today will be resolved. In line with the opinion of (Diener and Ryan, 2008), the relationship between religion and the practice of spirituality is paradoxical. A religious person tends to have a higher sense of well-being, and it is more specific about matters of participation in faithful service, affiliation, a relationship with God, and praying. Older people get a better appreciation of the meaning of life from religion, as well as life satisfaction, self-esteem, and higher optimism (Lifshitz, Nimrod, Bachrur, 2009).

The use of this index can be preventive and part of an evaluation related to the well-being of the elderly in Surabaya. The use of indices in both the municipal and central governments. It is useful for measuring the well-being categories of each region. The areas with low elderly well-being categories are to be used for an evaluation of the elderly well-being programs. Based on the results of the study, it can be noted that the Surabaya urban elderly well-being index has an average value. It can be declared that the elderly in 
Surabaya are in the prosperous category. Based on the formulation of the well-being index of the elderly, it is known that the most significant contribution is that the elderly can be biased in terms of well-being, environmental factors, health services, and spiritual well-being. In line with (Fleuret and Atkinson, 2007), they state that achieving success with the well-being index of the elderly must be supported by all aspects of life. The elderly can prepare themselves to face old age in a manner that is prosperous, productive, and meaningful. The strategy to become a friendly city for the elderly in 2030 requires an improvement of the indicators that achieved low, which does not require a lot of money. The results of this study can be used as input in the data assessment. Reconstruction is needed to plan towards having an elderly-friendly city (Kemenkes RI, 2013).

The limitations of the study were the sample consisted of the elderly, who live with their families. It did not include the elderly in nursing homes or the elderly who are being treated in hospitals. The measurement of the indicators for physical wellbeing is limited to the instruments of daily ability. Psychological well-being also did not look at the level of depression in the elderly.

\section{CONCLUSION}

Based on the above results, the indicators of elderly well-being are demographics, the health services available, the social environment, physical well-being, psychological well-being, social well-being, and spiritual well-being. The well-being indicators are expected to be a measuring tool that is a component of the well-being index. This study was useful as an evaluation of the elderly well- being in a manner that can be applied to policies and programs to improve the health of the elderly in both the regional and central government areas. The results can be used as a tool for improvement related to the elderly program to make the age-friendly city more optimal.

\section{REFERENCES}

Bps, K. (2018) Statistik Penduduk Lanjut Usia. Jakarta: Badan Pusat Statistik.

Burhan Bungin (2005) Metodologi penelitian kuantitatif. Jakarta: Kencana.

Burton, E. J., Mitchell, L. and Stride, C. B. (2011) 'Good places for ageing in place: development of objective built environment measures for investigating links with older people's wellbeing', BMC Public Health. BioMed Central Ltd, 11(1), p. 839. doi: 10.1186/1471-2458-11-839.

Diener, E. and Ryan, K. (2008) 'Subjective well-being : a general overview', 39(4), pp. 391-406.

Elo, S. and Isola, A. (2011) 'The physical, social and symbolic environment supporting the well-being of home-dwelling elderly people', (February). doi: 10.3402/ijch.v70i1.17794.

Erpandi (2015) Posyandu lansia mewujudkan lansia sehat, mandiri dan produktif. Jakarta: EGC.

Fave, A. D. et al. (2018) 'Promoting Well-Being in Old
Age : The Psychological Benefits of Two Training Programs of Adapted Physical Activity', 9(May), pp. 1-13. doi: 10.3389/fpsyg.2018.00828.

Fleuret, S. and Atkinson, S. (2007) 'Well-being, health and geography: A critical review and research agenda', pp. 106-118.

Global AgeWatch Insight (2018) Global AgeWatch Insight. HelpAge International.

Gomez, R. and Fisher, J. W. (2016) 'development and validation of the Spiritual Well-Being Questionnaire . Domains of spiritual well-being and development and validation of the Spiritual Well-Being Questionnaire', 35(January 2003). doi: 10.1016/S0191-8869(03)00045-X.

Hermawati, I. (2015) Kajian tentang kota ramah lanjut usia, Kajian Tentang Kota Ramah Lanjut Usia. Yogyakarta.

Hyde, A. L., Maher, J. P. and Elavsky, S. (2013) 'Enhancing our understanding of physical activity and well-being with a lifespan perspective', 3, pp. 98-115. doi: 10.5502/ijw.v3i1.6.

Ivankina, L. and Ivanova, V. (2016) 'Social well-being of elderly( based on the survey results )', 01046, pp. 1-5.

Kirkwood, T. B. L. and Cooper, C. L. (2014) Well-being: A Complete Reference Guide, Well-being in Later Life Volume 4 dari Well-being: A Complete Reference Guide Wiley Clinical Psychology Handbooks. John Wiley \& Sons.

Lifshitz, R., Nimrod, G. and Bachner, Y. G. (2019) 'Spirituality and well-being in later life: a multidimensional approach Spirituality and wellbeing in later life : a multidimensional approach', Aging \& Mental Health. Taylor \& Francis, 0(0), pp. 1-8. doi: 10.1080/13607863.2018.1460743.

Na, L. and Streim, J. E. (2017) 'Psychosocial WellBeing Associated With Activity of Daily Living Stages Among Community-Dwelling Older Adults'. doi: $10.1177 / 2333721417700011$.

Othman, A. R. and Fadzil, F. (2020) 'Influence of Outdoor Space to the Elderly Well-being in a Typical Care Centre', Procedia - Social and Behavioral Sciences. Elsevier B.V., 170, pp. 320329. doi: 10.1016/j.sbspro.2015.01.042.

Papalia, D. E., Olds, S. W. and Feldman, R. D. (2009) Human Development International student edition. McGraw-Hill.

Roberts, C. E. et al. (2017) 'Effect of different types of physical activity on activities of daily living in older adults: Systematic review and metaanalysis', Journal of Aging and Physical Activity, 25(4), pp. 653-670. doi: 10.1123/japa.2016-0201.

Ryff, C. D. (2014) 'Psychological Well-Being Revisited : Advances in the Science and Practice of Eudaimonia', pp. 10-28. doi: 10.1159/000353263.

Wiliyanarti, P. F. et al. (2017) 'FAMILY ENVIRONMENT AND PUBLIC (SOCIAL), INDEPENDENCE ELDERLY, THE ACHIEVEMENT OF WELFARE OF ELDERLY', in The Proceeding of 8th International Nursing Conference "Education, Practice And Research Development In Nursing". 
Surabaya: Fakultas Keperawatan Universitas Airlangga, pp. 385-388.

Wiliyanarti, P. F. (2018) Buku Ajar Gizi dan Diet. Surabaya: UMSurabaya Publishing.

Wiliyanarti, P. F., Asri, A. and Putra, K. W. R. (2018) 'Developing Holistic Care Model: the Physical Well-being of Elderly Based on Social Support and
Characteristic', Public Health of Indonesia, 4(3), pp. 108-115. doi: 10.36685/phi.v4i3.147.

Wiliyanarti, P. F., Notobroto, H. B. and Asri, K. (2017) 'The Effect of Social and Participation Environmental Factors on Achievement of The Well-being for Elderly', 5(6), pp. 71-78. 